\title{
An Information Storage-Retrieval System for Resource
}

\section{Managers}

\section{CARLA K. RATHBUN AND EDWARD E. STARKEY}

Highlight: An effective information storage and retrieval system is described. The system is inexpensive, and allows convenient cross referencing. It is especially useful for filing reprints and articles, but can also be used for photograhs, microfiche, research data, and various other items.

One of the most troubling problems facing resource managers and researchers alike is storage and retrieval of information. Most of us easily accumulate large numbers of reprints, publications, and assorted reports during a career. Finding a report or searching for information on a specific topic, however, is often difficult and time consuming.

Various systems have been developed to facilitate filing and retrieval of reprints or reports. Perhaps the most common method is to file individual documents in file drawers or boxes under a subject heading. Unfortunately, this system does not easily permit cross referencing. Often a report contains information on more than one topic, and it is difficult to determine the appropriate subject heading. Retrieval of such information, therefore, requires searching through many reports filed under different headings, a process that is often frustrating.

This difficulty can be mitigated partially by using a complementary card-filing system. Subject headings are established, and author-title cards are filed under each relevant heading. Thus, cross referencing is done by searching several different headings. This method requires the preparation of several cards for each report, one for each keyword, which makes cross referencing inconvenient.

Another technique utilizes edge-punched cards (Adams 1955; Bryan 1966). This system allows cross referencing, but requires a considerable amount of planning in the development of a filing code. In addition, edge-punched cards are expensive.

Of course, the ultimate system for storage and retrieval of information is a properly programmed computer. Many programs exist for such applications, but we found FAMULUS, developed by the Pacific Southwest Forest and Range Experiment Station o the U.S. Forest Service, to be highly satisfactory (Burton et al. 1969; Scharpf et al. 1976). We have complete bibliographic files for Crater Lake National

The authors are former secretary, Cooperative Park Studies Unit, Oregon State University, Corvallis, and research biologist, National Park Service, stationed at the School of Forestry, Oregon State University, Corvallis. Ms. Rathbun's current address is $121 \mathrm{~W}$ Haskeli, Winnemucca, Nevada 89445.

Manuscript received October 27, 1977
Park and John Day National Monument stored on tape, and we use the CYBER 73 computer at Oregon State University for search and retrieval. Unfortunately, many resource managers and field researchers do not have ready access to a computer.

For the last 2 years we have been using a manual system that allows efficient storage and retrieval of information and convenient cross referencing of several keywords. The system was originally developed for engineering applications and described by Conner and Nieves (1969). We have found this filing system to be very flexible and have adapted it for our own use in the areas of resource management and land-use planning. The system may be used for slides, photographs, or microfiche, as well as laboratory data, on-hand publications and reports, and material located in other areas, such as libraries.

\section{How to File an Article}

One need not purchase expensive punch cards or machinery. The cards used are 3 -inches by 5 -inches (or whatever size is desired).

When a publication is received that you wish to keep, it receives an accession number. The number is placed in either the upper left- or right-hand corner of the publication. The numbering of each successive article is continuous, regardless of topic or author. An accession card (3-inches by 5 -inches) then is assigned to the article. On this card is listed accession number of article, author, title, and other bibliographic information, including an abstract if you wish. A completed accession card for an article by Wright (1972) is shown in Figure 1. If the article is not located in your files, but you still value a reference to it, its location may be listed below the other data.

Keywords then are assigned to the article. These are words that accurately describe important topics discussed or otherwise allow ready retrieval of the article. The specificity and number of keywords are at the discretion of the individual who will be using the files. If you wish, you may list the keywords on the accession card (Fig. 1). Many technical journals now supply preprinted accession cards to which you need only affix an accession number.

The next step in filing this article can readily be done by a secretary or assistant. For each new keyword, a keyword card is prepared. We use 3 - by 5 -inch cards that have been preprinted, with no keywords or accession numbers. The accession number of this particular article is placed in a column corresponding to its last digit (Fig. 2). That is, if an article was No. 235, this accession number is listed under column 5 on the appropriate keyword cards. Listing by the last digit allows ready expansion of the system and provides an orderly column of numbers for easy viewing. Try to keep the digits directly below each other in the 
Wright, R. G. 1972. Computer processing of chart quadrat maps and their use in plant demographic studies.

J. Range Manage. 25(6):476-478.

Abstract: A film scanning computer system was used to rapidly process chart quadrat maps from the Jornada Experimental Range. The technique was successfully used in demographic studies of perennial grasses.

Keywords: Automatic data processing; chart quadrat maps; Jornada Experimental Range; plant demography; semi-desert grassland; Wright, R. G.

Fig. 1. Accession card.

columns for ease in viewing during cross referencing.

One keyword card may contain many accession numbers because many articles are similar and will have some keywords in common. If a keyword card already has been made out for a previous article, you will only need to list the accession number for this article in the appropriate column.

Once all keyword cards are completed and an accession card has been typed, the article is filed by accession number. The 3 - by 5 -inch cards are stored in file drawers, usually in the same area as the articles. One two-drawer set of files will accommodate several hundred 3- by 5inch cards. The accession cards and the keyword cards are filed in separate drawers.

\section{Finding a Reference}

When wishing to locate a particular article or information on a specific topic, first think of all possible keywords associated with that article or topic. Pull these keyword cards from the file. Arrange them vertically (Fig. 3).

This arrangement enables a quick visual comparison of accession numbers. Numbers that are common to two or more cards indicate reports that may contain desired information. By this process, looking through many articles to find the correct one has been eliminated. Usually, this cross comparison of keywords and accession numbers can bring down the search to five or fewer articles that may be of interest.

Now the keyword cards must be refiled before they are lost; this happens easily when they are laid aside. Having jotted down the pertinent accession numbers, go to the accession number card file. By spending a minute or two checking this file, searching through the more bulky article files can be eliminated. The title or abstract will allow selection of relevant articles without having to delve into the actual article files. Articles of interest then are retrieved easily by accession number.

\section{Advantages}

The primary advantage of the system is the ease with which

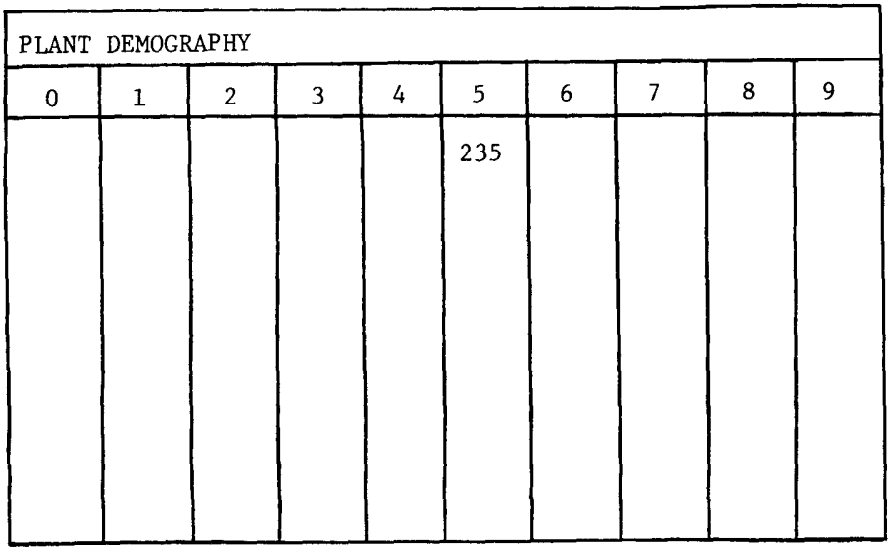

Fig. 2. Keyword card.

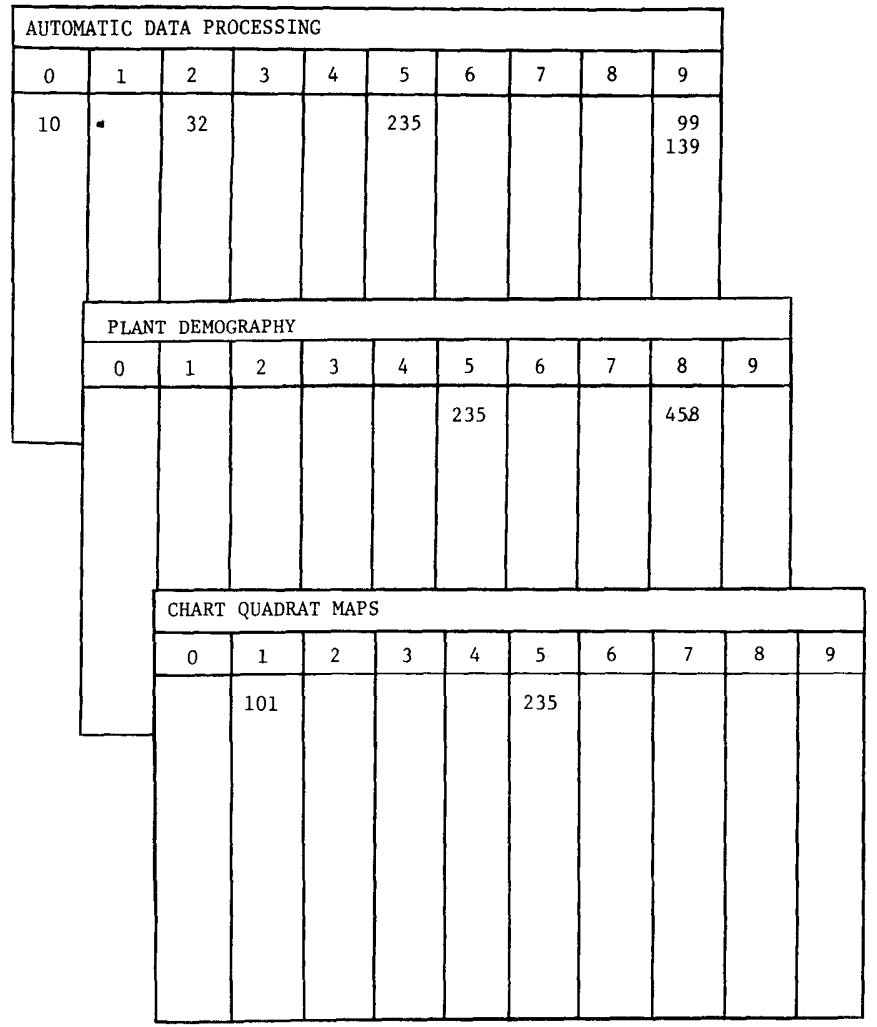

Fig. 3. Keyword cards associated with a particular article or topic.

information can be stored and retrieved. After the system has been in use for awhile, most keywords already will have been used previously. Therefore, additional keyword cards are not prepared, and storage of references is accomplished quickly, as is their retrieval. A search for a single keyword can be done in a few seconds. Cross referencing is more time consuming, but still can be done more quickly than with other noncomputerized systems. Our files contain over 1,200 reports and 1,600 keywords, and a search for articles with three keywords in common can be done in 60-90 seconds.

Another advantage is the low cost of setting up and maintaining the system. A two-drawer card file and filing cabinets of some sort for reports are the only equipment required, and 3- by 5-inch cards are inexpensive.

A secretary familiar with your work usually can do all of the keywording and filing. Material can be refiled easily. A note should be left in the article file for the material checked out.

One note of caution when using this system is that every effort should be made to keep the keyword cards in correct alphabetical order and in the file. If one keyword card is lost, the system loses its effectiveness. This loss may be prevented by having a central work area with the 3-by 5-inch card files. If users work on a table or desk with writing materials readily available, chances are the files will stay in better order. If several persons use the files, the cards should be checked occasionally.

\section{Literature Cited}

Adams, L. 1955. A punch-card bibliographic file for vertegrate ecologists. J. Wildl. Manage. 19:472-476.

Bryan, J. H. 1966. A multi-purpose information retrieval system based on edge-notched cards. Bioscience 16:402-407.

Burton, H. D., R. M. Russell, and T. B. Yerke. 1969. FAMULUS: A computer based systemf or augmenting personal documentation efforts. U.S. Dep. Agr. Forest Serv. Res. Note PSW-193. 5 p.

Conner, H. W., and J. Nieves. 1969. Technical information retrieval. Civil Engineering 39:47-50.

Scharpf, R. F., F. G. Hawksworth, and B. J. Erickson. 1976. Mistletoe literature of the world: a users guide to a FAMULUS Retrieval System. U.S. Dep. Agr. Forest Serv. Gen. Tech Report RM-30. 5 p.

Wright, R. G. 1972. Computer processing of chart quadrat maps and their use in plant demographic studies. J. Range Manage. 25:476-478. 